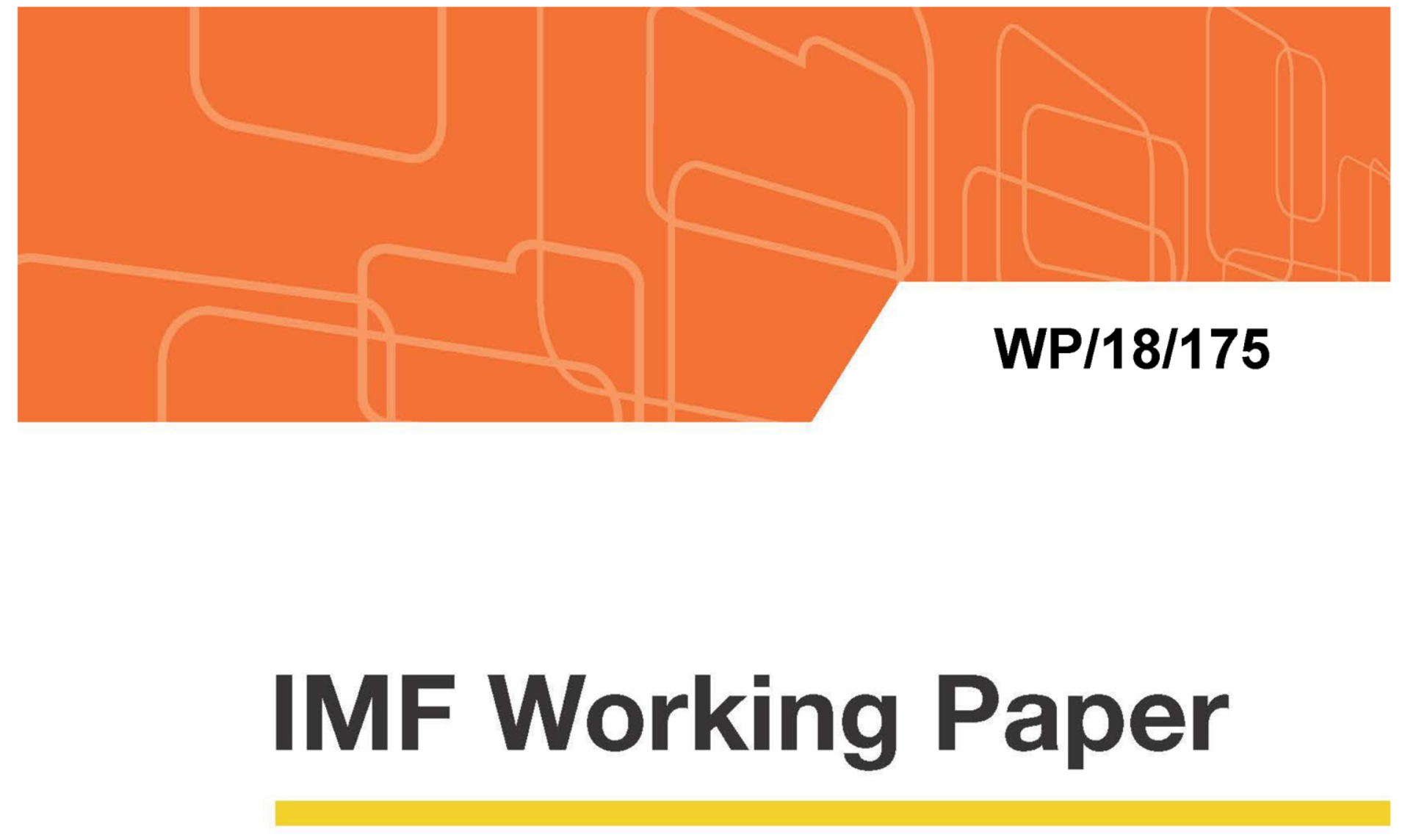

\title{
Using Administrative Data to Enhance Policymaking in Developing Countries: Tax Data and the National Accounts
}

by Lisbeth Rivas and Joe Crowley

IMF Working Papers describe research in progress by the author(s) and are published to elicit comments and to encourage debate. The views expressed in IMF Working Papers are those of the author(s) and do not necessarily represent the views of the IMF, its Executive Board, or IMF management. 


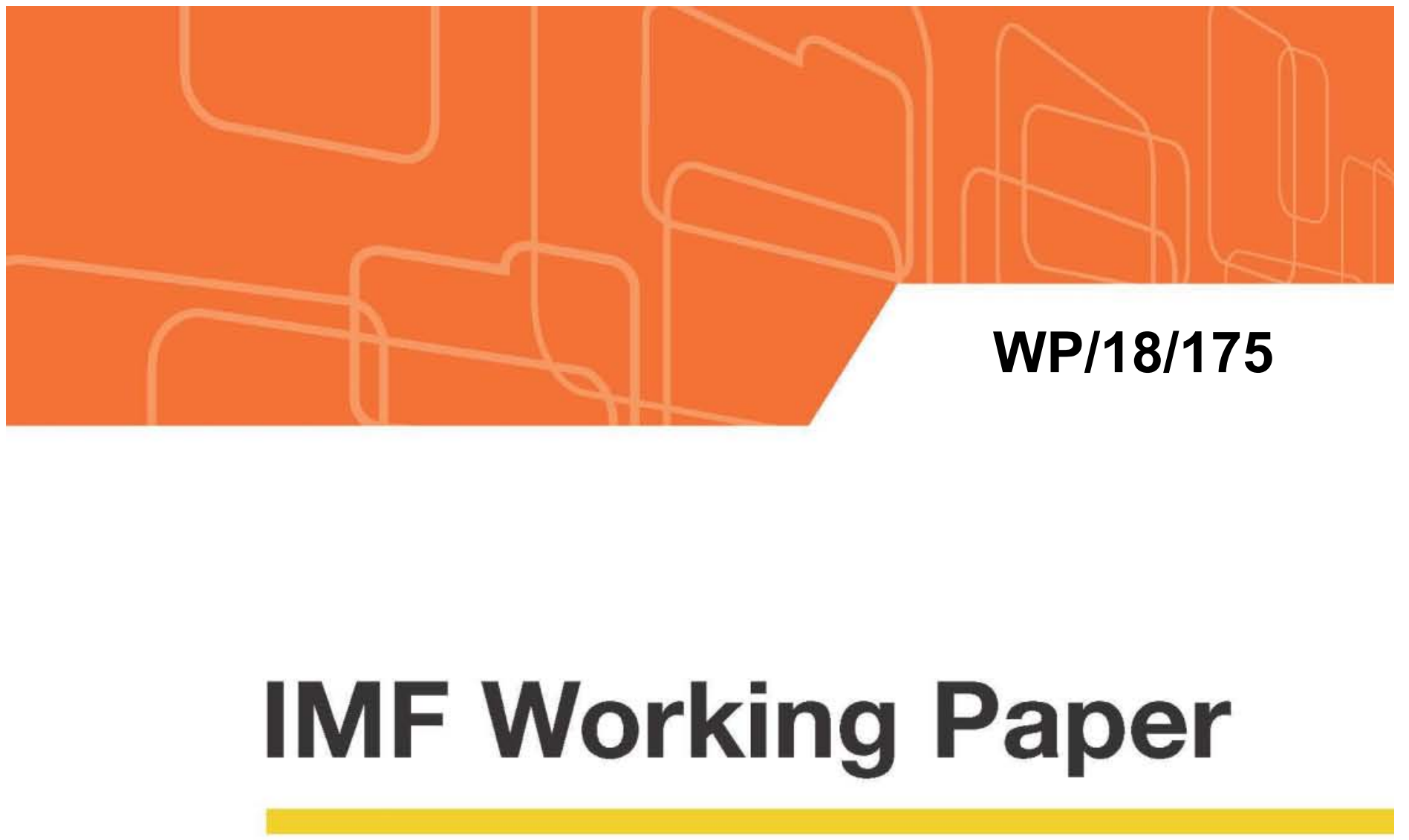

\section{Using Administrative Data to Enhance Policymaking in Developing Countries: Tax Data and the National Accounts}

by Lisbeth Rivas and Joe Crowley

IMF Working Papers describe research in progress by the author(s) and are published to elicit comments and to encourage debate. The views expressed in IMF Working Papers are those of the author(s) and do not necessarily represent the views of the IMF, its Executive Board, or IMF management. 
(C) 2018 International Monetary Fund

$\mathrm{WP} / 18 / 175$

\title{
IMF Working Paper
}

Statistics Department

\section{Using Administrative Data to Enhance Policymaking in Developing Countries: Tax Data and the National Accounts}

Prepared by Lisbeth Rivas and Joe Crowley ${ }^{1}$

Authorized for distribution by Claudia Dziobek and Patrizia Tumbarello

August 2018

IMF Working Papers describe research in progress by the author(s) and are published to elicit comments and to encourage debate. The views expressed in IMF Working Papers are those of the author(s) and do not necessarily represent the views of the IMF, its Executive Board, or IMF management.

\begin{abstract}
Statistical agencies worldwide are increasingly turning to new data sources, including administrative data, to improve statistical coverage. Administrative data can significantly enhance the quality of national statistics and produce synergies with tax administration and other government agencies, supporting better decision making, policy advice, and economic performance. Compared to economic censuses and business surveys, administrative data are less burdensome to collect and produce more timely, detailed, and accurate data with better coverage. This paper specifically explores the use of value added tax and income tax records to enhance the compilation of national accounts statistics.
\end{abstract}

JEL Classification Numbers: B41, C81, C82, C83, H20, M40, M48, O49

Keywords: Administrative Data, Tax Data, National Accounts, Value Added Tax

Authors' E-Mail Address: 1rivas@imf.org, jcrowley@imf.org

\footnotetext{
${ }^{1}$ The authors are grateful to Enriko Aav, Elias Albagli, Katherine Baer, Dora Benedek, Robert Dippelsman, Claudia Dziobek, Russel Freeman, Elizabeth Gavin, Martin Knudsen, Andrew Masters, Clement Ncuti, Gabriel Quiros, Roberto Rosales, Andrea Schaechter, Mick Thackray, Patrizia Tumbarello, Louis Venter, and other participants in the March 2017 Statistics Department Brown Bag Seminar for helpful comments and suggestions on an early draft of this paper. As part of a successful collaboration with the Fiscal Affairs Department, a "howto" note on cooperation between tax authorities and national statistics offices is in progress.
} 


\section{Table of Contents}

Abstract

I. Introduction $\underline{5}$

II. Using Tax Data to Enhance Compilation of National Accounts Statistics $\underline{6}$

III. Data Sharing and Confidentiality $\underline{8}$

IV. Cooperation Between Tax Authorities and National Statistical Offices $\underline{9}$

V. Coverage of the Tax Base 10

VI. Rough Edges

A. Variations in Compliance 12

B. Time of Recording 12

C. Classification $\underline{13}$

D. The Informal Sector

VII. Taxpayer Registries and National Accounts Business Registers 14

VIII. Use of Tax Data in the National Accounts: Some Country Experiences $\underline{15}$

IX. Conclusion

References

Figure

1. Collaboration Between Tax Authorities and National Statistics Offices $\underline{10}$

Table

1. Adequacy of Taxpayer Data Coverage for National Accounts Purposes 11

Appendices

I: Tools Providing an Indication of the Coverage of Tax Records: ISORA/RA-FIT, RA-GAP and TADAT

II: Sample Memoranda of Understanding (MOU)

$\underline{26}$




\section{Glossary}

$\begin{array}{ll}\text { GST } & \text { Goods and Services Tax } \\ \text { ISIC } & \text { International Standard Industrial Classification } \\ \text { ISORA } & \text { International Survey on Revenue Administration } \\ \text { MIEA } & \text { Monthly Index of Economic Activity } \\ \text { MoU } & \text { Memorandum of Understanding } \\ \text { NISR } & \text { National Institute of Statistics of Rwanda } \\ \text { NSOs } & \text { National Statistics Offices } \\ \text { ONS } & \text { Office of National Statistics } \\ \text { PAYE } & \text { Pay as You Earn } \\ \text { RA-FIT } & \text { IMF Revenue Administration Fiscal Information Tool } \\ \text { SDGs } & \text { Sustainable Development Goals } \\ \text { UBoS } & \text { Uganda Bureau of Statistics } \\ \text { UES } & \text { Unified Enterprise Survey } \\ \text { URA } & \text { Uganda Revenue Authority } \\ \text { VAT } & \text { Value Added Tax }\end{array}$




\section{INTRODUCTION}

Administrative data can significantly enhance the quality of national statistics, thus contributing to better policymaking and economic performance. More timely, detailed, and accurate data allow for quicker and better-targeted policy responses to fluctuations in macroeconomic indicators. A decline in revenue, the start of a recession, or a divergence in the balance of payments can be addressed sooner and more effectively the faster policymakers are informed of the development and the more accurately the deviation in activity is measured. Furthermore, more detailed data can enable narrower targeting of policies, for example, when designing social programs or macroprudential policies that are intended to impact only certain groups or activities. These data are beneficial to national policymakers, to international institutions that monitor national economies and provide policy advice, and to domestic businesses and individuals and external creditors who need to make informed investment and lending decisions.

Statistical agencies worldwide are increasingly turning to the use of administrative data to improve statistical coverage. This is part of a broader effort to use data sources that rapidly advancing technology is making increasingly accessible. Administrative data are typically targeted to a purpose other than statistical or research needs, and thus may not be exactly aligned with those needs, but they can nevertheless be useful to statisticians or researchers. Significant resources may have been devoted to their collection, resulting in good coverage, quality, and timeliness, and the cost of transferring and adapting them for statistical purposes can be well below the cost of collecting other data from scratch.

\section{Administrative data can be used as a source to enhance traditional macroeconomic statistics. There is a growing demand for more detailed and granular economic data, and satisfying these demands will become increasingly difficult with the amount of resources that are likely to be available. It will be essential to leverage new technologies and administrative data sources to collect statistical information more efficiently. As automation advances, economic surveys become easier to complete and submit, yet compared to new data collection methods they remain time-consuming, expensive, impose significant reporting burdens, and result in long reporting lags, and households and enterprises have increasingly limited patience for them. National statistics offices (NSOs) have responded, coordinating their data collection, jointly designing surveys with other agencies, and offering user-friendly methods of responding electronically, but they need to make and are making better use of existing administrative data. In some countries, this is even mandated by legislation.}

Administrative data can enhance a wide range of datasets. This paper illustrates how tax data can be used to improve the timeliness, coverage, and quality of national accounts data, but this is just one way in which administrative data can be used to improve economic 
statistics. ${ }^{2}$ Health, education, and welfare records can be used to verify expenditure data as well as to measure the impact of expenditures, including the effectiveness of social safety nets. Demographic administrative data (births, deaths), social security, and migration statistics can complement census records. There are also benefits to merging these records with one another and with tax data. ${ }^{3}$

Greater recognition of and access to the benefits of administrative data have led to their adoption in an increasing number of countries. Advanced economies have long made these data a key element of their national statistical data collection. As the advantages of this information and the feasibility of adapting them to statistical purposes become more apparent, and as technology has facilitated their collection and adaptation, a widening range of countries at all levels of development has been able to make use of them. Some countries with limited resources are particularly interested in the short-term cost saving benefits, in addition to the longer-term surveillance and policy response benefits.

\section{Using Tax Data to Enhance Compilation of National Accounts Statistics}

This paper explores the use of tax records to enhance the compilation of national accounts statistics. These records can support the annual and quarterly national accounts, and a monthly index of economic activity (MIEA). These series together provide a comprehensive picture of economic activity in a country. The usefulness of these data for tax policy analysis is articulated in Grote 2017.

Tax data contain information that can be used in compiling national accounts. Through engagement between NSOs and Tax Administrations differences in concepts and definitions used in tax data and national accounts can be identified and addressed in order to use tax records for national accounts compilation purposes. Definitions used in taxation are often broadly comparable to those used in the compilation of national accounts, facilitating their reorganization for national accounts compilation purposes. VAT data can be especially useful for tracking new industries and business models (even if some new taxpayers are unaware of or resistant to their obligation to pay taxes), and for estimating activity in industries that represent small shares of GDP where devoting limited resources to surveys might not be justified. Because of the obvious disincentive to report, they can be less complete than other business data, but can supplement those data, or can be used to cross-check company accounts.

\footnotetext{
${ }^{2}$ Other sources of data (auto sales, airline travel, motion picture admissions, etc.) can be useful in estimating national accounts, though the owners of these data may not provide them free of charge.

${ }^{3}$ For example, education records can be merged with tax data to understand returns to education. Firm data on taxes paid or sales can be compared with bank data or customs data to compare activity with debt and international connectedness.
} 
National value added is calculated by subtracting intermediate consumption from output. Once output and intermediate consumption in a base year are compiled, growth rates of taxes paid can be applied to these figures to estimate national accounts for subsequent periods. VAT turnover or sales may be good proxies for output (assuming unchanged inventories, though in some cases the cyclicality of inventories can undermine this assumption). Enterprise level monthly VAT data provide information on sales and purchases, and purchases can be used as proxies for intermediate consumption. ${ }^{4}$. When financial statements are available, corporate income tax records can be used to compile detailed production accounts, income accounts, financial accounts, and balance sheets of non-financial corporations, allowing for the calculation of value added, saving, investment, and net lending.

Financial sector tax records are less useful for compiling national accounts. For national accounts purposes, financial sector output is measured as lending income (the lending rate times the stock of loans) minus payments to depositors (the deposit rate times the stock of deposits). ${ }^{5}$ For VAT tax purposes, however, financial activity is usually exempt. Because there is no sale, net interest earnings are not recorded as tax transactions; rather gross interest revenue is measured. Interest costs can be deducted from gross revenue to arrive at a comparable figure for net interest income, but the calculation of interest costs using tax accounts is complicated and cumbersome, and the net return to the tax authority of tracking these earnings would be very low.

Countries with limited statistical capacity or weak governance structures may face more obstacles. Agencies may be reluctant to share data with NSOs if they see that the NSOs have little to offer in return, or if there is a lack of trust in NSOs that could raise confidentiality concerns; these concerns can be mitigated by good engagement between NSO and tax authority staff on how to maintain the confidentiality of source data within their respective organizations. NSOs may lack the resources to convert or to make use of the administrative data despite their low cost and high usefulness. In any NSO, the collection of administrative data will require additional knowledge, skills, and resources, as will the opportunities for useful analysis that the new data may offer. In such cases collaboration beyond working together on the industry structure may be difficult.

\footnotetext{
${ }^{4}$ The detail contained in VAT returns varies. Some returns may not differentiate between capital and non-capital goods, or may not include VAT exempts goods and services or the consumption or output of zerorated goods. Issues such as these can readily be clarified through engagement with the tax authority.

${ }^{5}$ Financial intermediation services indirectly measured (FISIM). See Commission of the European Communities, International Monetary Fund, Organization for Economic Co-operation and Development, United Nations, and World Bank, System of National Accounts 2008, Pages 155 and 116.
} 


\section{DATA Sharing ANd CONFIDENTIALITy}

Data sharing mechanisms vary across countries, and many need to be formalized and strengthened. Careless or undocumented sharing of taxpayer information can weaken confidence in the tax authority and erode tax compliance. Many tax authorities simply exchange records with NSOs using informal networks, even though this is not recommended. Some countries enhance their data sharing frameworks with memoranda of understanding (MoUs), but ideally legislation should detail requirements for and restrictions on sharing of data, both to maintain trust in the tax authority and to ensure continuous access to the data. In many countries (UK, South Africa), tax administration records are made available in "data laboratories".

The sharing of confidential tax data between tax authorities and NSOs can raise confidentiality concerns. There can be legal requirements or guidelines that restrict the sharing of information, but confidentiality concerns can arise even if there are no explicit rules that require it.

To address this concern, some tax authorities allow the sharing of detailed information without directly identifying taxpayers. Tax authorities can withhold identifying information, generating identification numbers for companies or individuals in place of names. Some general characteristics of businesses might be included in transferred records (activity, size). Removing names does not guarantee perfect anonymity - it may be possible to identify the richest person in the country or the largest bank. But for most taxpayers this system could provide satisfactory privacy. Any published data would be aggregated and redacted of any information that could potentially identify taxpayers. Such restrictions on the sharing of personal or confidential details may limit the usefulness of the shared data for the NSO, but it can ensure that at least the limited data can be transferred reliably.

A further layer of security can be added by restricting access to tax records to a very limited group of NSO staff. Tax authorities can agree to provide detailed records, including data at the enterprise level, only to designated NSO staff, or perhaps permitting them to extract and keep only aggregate information (another limitation on the usefulness of the data). NSO staff should be accustomed to legal requirements that treat data confidentially, and should recognize that the data they access are to be used exclusively for statistical purposes. In some cases, NSO staff use of confidential data may be tracked and audited. Sanctions that apply in case of breaches of security should be clarified (OECD 2015).

External risks need to be addressed. The NSO should be able to ensure that data transmitted from the tax authority or from any other institutions are secure from hackers. Of course, the same issue arises for the tax authority anytime it transmits data, and there is thus scope for cooperation between tax authorities and NSOs on data security. 


\section{CoOperation Between Tax Authorities ANd National Statistical Offices}

Cooperation between tax authorities and NSOs is important, and is most effective when it is advantageous for both parties (Figure 1). The NSO, as the recipient of tax administration data, is an obvious beneficiary of any arrangement, however there are also ways in which the tax authority can benefit from the NSO. For example, the NSO can assist the tax authority with data quality and ISIC industry coding. The two institutions can cooperate on data security. The tax authority's tax registry and the NSO's business register can be compared to detect errors and unregistered taxpayers, provided the legal framework permits this. In many countries, the tax authority maintains the tax registry using taxpayer registrations, and the NSO maintains the business register to draw samples of enterprises for conducting surveys, an avoidable duplication of work.

\section{MoUs between the tax authority and the NSO are beneficial for providing clarity and} continuity. It can promote a commitment to provide data reliably and regularly by indicating that data will be shared for statistical purposes only, providing a schedule for its regular provision, and specifying the format in which it will be provided. It can also include procedures for harmonization of coding, and clarify security and confidentiality measures. ${ }^{6}$ In some countries, informal contacts are relied on, but this is less effective for a variety of reasons, including information security risks and staff turnover, and should not be endorsed. ${ }^{7}$ An MoU can also help ensure engagement at a senior level. Some countries even include provisions for access to tax data by NSOs in their statistics acts.

Two sample MoUs are included in Appendix II: one for Uganda and another for The Gambia. The MoU for Uganda formalizes the procedures relating to the flow of accurate and timely domestic tax data between the Uganda Bureau of Statistics (UBOS) and the Uganda Revenue Authority (URA). These data form a vital element in the compilation of GDP (in current and constant prices). The MoU for The Gambia relates to the coordination, sharing, updating and periodic reporting of VAT and business register data between the Gambia Revenue Authority (GRA) and the Gambia Bureau of Statistics (GBoS). The VAT data are used in the compilation of quarterly GDP estimates and the development of the business register.

A robust system of data validation and quality checks should be established between the NSO and the tax authority. This should include an open dialogue on data issues, such as feedback and early warning of potential changes (format, content, classification, etc.). Detailed data validation can be streamlined by concentrating on larger companies when validating all records is impractical, which is usually the case.

\footnotetext{
${ }^{6}$ Examples of developing countries with MoUs include Costa Rica, Rwanda, Tonga, and Uganda.

${ }^{7}$ Cook Islands, Ethiopia, Fiji, Liberia, Papua New Guinea, Samoa, Tanzania, Tunisia, and Vanuatu are some examples of countries that rely on informal networks.
} 
Figure 1. Collaboration Between Tax Authorities and National Statistics Offices

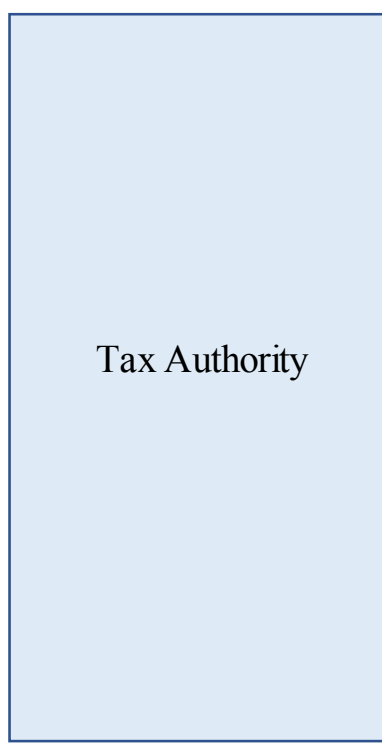

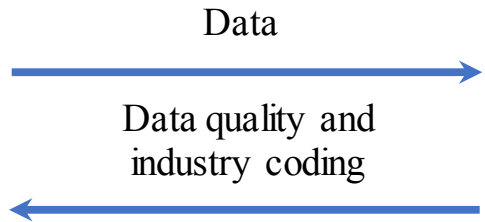

Broadening the tax base

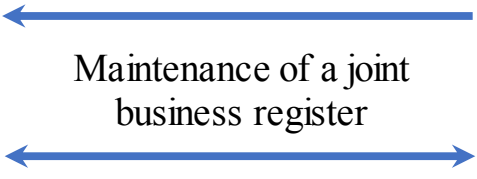

Data security

Source: IMF staff.

Collaboration between tax authorities and NSOs can lead to broader cooperation between national institutions. In some countries communication between national institutions, for example the Central Bank and the Ministry of Finance is weak. NSOs working with multiple agencies to collect and cross check administrative data can help establish beneficial lines of communication between those agencies.

\section{Coverage OF The TAX BaSe}

Tax data must have adequate coverage to be useful in compiling national accounts. A general rule of thumb accepted by many national accounts statisticians is that registration and on time filing rates should be at least 60 percent. ${ }^{8}$ These rates may vary significantly across taxpayer categories, and are generally higher among large taxpayers (Lemgruber and others, p. 34). Thus, a tax compliance rate of 60 percent may cover more than 60 percent of GDP (though it may also represent a biased sample). In some countries, tax authorities share data from the large taxpayers unit. When compliance rates are low, statisticians may revert to surveys, though these may also be substandard in such cases, and statisticians may therefore consider working proactively with tax policy units. In any case, even incomplete tax data can usefully complement survey data or provide estimates in industries where survey data are

${ }^{8}$ On-time filing rates are calculated as the ratio of the number of returns that were received to the number of returns that were expected. Registration rates are calculated as the ratio of active taxpayers to the total number of taxpayers. 
sparse or not available. And surveys by NSOs are likely to have lower response rates than tax declarations, which often carry penalties for nonrespondents.

\begin{tabular}{|c|c|c|c|c|c|c|}
\hline \multicolumn{7}{|l|}{$\begin{array}{l}\text { Table 1. Adequacy of Taxp } \\
\text { (Average rates, in percent) }\end{array}$} \\
\hline \multicolumn{7}{|l|}{ Registration rates } \\
\hline \multirow[t]{3}{*}{ Income tax on corporations and other entities } & Low income & 75.0 & 76.3 & 74.2 & $\ldots$ & $\ldots$ \\
\hline & Lower middle income & 64.5 & 63.5 & 71.5 & $\ldots$ & $\ldots$ \\
\hline & Upper middle income & 68.0 & 68.0 & 70.2 & $\ldots$ & $\ldots$ \\
\hline \multirow[t]{3}{*}{ Individual income tax } & Low income & 76.7 & 74.6 & 75.3 & $\ldots$ & $\ldots$ \\
\hline & Lower middle income & 76.3 & 75.9 & 69.8 & $\ldots$ & $\ldots$ \\
\hline & Upper middle income & 66.2 & 64.3 & 64.1 & $\ldots$ & $\ldots$ \\
\hline \multirow[t]{3}{*}{ VAT tax } & Low income & 85.3 & 87.7 & 85.1 & $\ldots$ & $\ldots$ \\
\hline & Lower middle income & 71.7 & 68.3 & 72.8 & $\ldots$ & $\ldots$ \\
\hline & Upper middle income & 66.2 & 65.0 & 71.5 & $\ldots$ & $\ldots$ \\
\hline \multicolumn{7}{|l|}{$\underline{\text { On-time filing rates }}$} \\
\hline \multirow[t]{3}{*}{ VAT Returns } & Low income & 67.7 & 64.2 & 71.0 & 73.4 & 76.7 \\
\hline & Lower middle income & 62.7 & 63.9 & 66.4 & 76.4 & 77.2 \\
\hline & Upper middle income & 71.7 & 72.1 & 70.2 & 75.3 & 73.1 \\
\hline \multirow[t]{3}{*}{ Corporate income tax returns } & Low income & 64.1 & 67.3 & 62.3 & 74.4 & 76.0 \\
\hline & Lower middle income & 46.5 & 47.6 & 51.1 & 58.5 & 58.1 \\
\hline & Upper middle income & 48.3 & 52.7 & 58.3 & 62.0 & 61.7 \\
\hline
\end{tabular}

Source: IMF Revenue Administration Fiscal Information Tool (RA-FIT) Data Portal.

Tax coverage in most countries is adequate for compilation of annual national accounts. In revenue administration surveys covering the fiscal years 2011-15, VAT and income tax on time filing rates were found to be well above the benchmark rate of 60 percent for most reporting countries. In all years, across three different income groups, the average taxpayer registration rates exceed 60 percent for corporate, individual income, and VAT taxes (Table 1). ${ }^{9}$ The on-time VAT tax return filing rates also exceed 60 percent, and while on-time corporate tax filing rates exceed 60 percent only for LICs and UMIs, there was a general improvement from 2011 to 2015 . It should be noted that on-time plus delayed filing rates could be substantially higher. ${ }^{10}$

Coverage is less comprehensive for quarterly tax data. In most countries, only annual income tax returns are required. Businesses in some countries provide monthly or quarterly returns, but even in these cases the annual income tax data typically cover four to five times

\footnotetext{
${ }^{9}$ The averages conceal wide disparities across countries, with some countries reporting rates as low as 10 percent.

10 This information is available on the web-based Revenue Administration Fiscal Information Tool (RA-FIT), designed by the Fiscal Affairs Department of the IMF to establish baselines of current revenue administration performance. The data that it tracks include taxpayer registration and tax return filing rates. (Appendix I).
} 
as many businesses. If quarterly data are needed, detailed annual data can be combined with partial quarterly data to generate quarterly estimates. ${ }^{11}$

\section{Rough Edges}

Administrative data typically need to be reorganized before they can be used for statistical purposes as they are designed for different purposes. In general, however, administrative data can be transformed to capture most of their value. In some cases, the needed transformations are small enough to be simply ignored and still result in useful data.

\section{A. Variations in Compliance}

Tax policies, provisions, and practices may change over time. Changes in filing obligations can affect who reports taxes; countries often introduce legislation to deliberately broaden the tax base. There can also be changes in the required frequency of filing, information requirements, or thresholds for VAT registration. Concepts and definitions can change, as can the types of entities that are covered (taxation by group, by enterprise, or by establishment).

Tax compliance may vary over time. Changes in the taxpayer registry or in tax revenues need to be separated into those that reflect changes in economic output (entry, exit, or changes in the activity of firms) versus those that do not (existing firms that start or stop reporting or change their reporting methods). Some fluctuations occur simply as a result of statistical anomalies such as missing values, which can be corrected for, but others can be more difficult to track. In some countries where tax administration systems are still developing there are rapid improvements in tax compliance and expansion of tax bases, which complicates the tracking of tax compliance, particularly for developing countries that may lack resources and independent data sources. ${ }^{12}$

Tax evasion (reluctance to report income on which tax is due) is a common source of variable compliance. Tax evasion can be negatively correlated with GDP growth and can thus distort the relationship between taxable income and GDP, leading to exaggerated estimates of fluctuations in output if not corrected (Allingham and Sandmo, 1972). But variations in the taxable income to GDP ratio are not necessarily due to tax evasion; legal tax waivers or tax holidays can complicate also the relationship between tax revenues and GDP. A particularly problematic case is that of tax waivers for new investors, since this may result in firms that enter the economy and begin producing without being captured by tax records until months or years later. The tax waivers may be granted by an institution other than the tax authorities, making them especially difficult to track by NSOs.

\footnotetext{
11 This can be done by aligning the annual totals of the quarterly data with those of the annual data while maintaining the quarterly growth rates.

12 See discussion on the RA-GAP program in Appendix 1.
} 
Finally, tax data cover a biased sample of economic activity. Households and corporations that report taxes may differ in important ways from ones that don't report taxes, and trends in the economic activity of the former group may not exactly align with trends in that of the latter. While good estimates might be arrived at by simply ignoring different economic trends in the latter group, ideally methods such as calibration against independent data sources can be used to fine tune the results. (See "The Informal Sector" on Page 14.)

\section{B. Time of Recording}

The timing of tax payments often differs from the timing of the underlying economic activity. Tax data are frequently recorded on a cash basis (upon payment), while national accounts data are compiled on an accrual basis (when the economic activity takes place). The most useful tax data for estimating national accounts are found in industries where the timing of tax payments is most closely aligned with that of the underlying economic activity. Examples of such industries are mining and quarrying, much of manufacturing, hotels and restaurants, transportation, and communications. Construction is an example of an industry in which the timing is not well-aligned, because large projects can take years to conclude and tax payments are often deferred until completion even though the economic activity takes place over months or years. In retail and wholesale industries, where output is measured as sales minus purchases, sales may occur long after the merchandise to be sold is purchased. In the national accounts, the value added is recorded when the final sale is made even if the payment for the sale is delayed (credit). In the tax data, purchases (intermediate consumption) and sales (output) of goods and services are recorded when the tax is paid, even though they may occur at very different times. This complicates the calculation of value added (output minus intermediate consumption).

There are other timing issues to address. These include non-reporting in some periods, late reporting, frequency mismatches, seasonality, and different reporting periodicities (e.g. large enterprises may report data monthly, medium enterprises quarterly, and small enterprises annually). Survey data share some of these problems.

\section{Classification}

The industry classification of economic activities may not be consistent between tax authorities and NSOs. NSOs classify national accounts data according to the International Standard Industrial Classification (ISIC). ${ }^{13}$ Tax authorities ideally should do the same, and they generally have more detailed coverage of enterprises than NSOs do, but often they use more informal classification methods, such as using different or less structured industry classifications. For example, they may permit companies to select their own classification category, and enterprises with multiple economic activities may not classify themselves according to their principal ISIC activity (and enterprises that do this are often larger ones

${ }^{13}$ ISIC Revision 4, (United Nations 2008). 
that account for a large share of GDP). Tax data are most closely aligned with national accounts concepts for large, homogeneous samples of enterprises by industry and size.

\section{The Informal Sector}

NSOs are able to estimate informal sector activity. This activity is generally not captured by tax data. Estimates of informal sector activity made by NSOs can be useful to tax authorities in increasing compliance and broadening the tax base, and thus represent a prime opportunity for mutual benefit between the agencies. The informal sector includes many small businesses - including some engaged in illegal activity - that are able to operate without being noticed or pursued, but it also includes larger enterprises that are able to operate without seeking licenses or otherwise registering in ways that would attract the attention of the tax authority. Estimates of informal sector activity can provide information on the scope of possible tax evasion (although the NSO should normally play no role in addressing these issues).

\section{TAXPAYER Registries AND NATIONAL ACCOUNTS Business Registers}

It may be possible to consolidate separate lists of businesses and individuals maintained by tax authorities and NSOs. Tax authorities maintain taxpayer registries, while NSOs maintain business registers. These lists are similar, but in many countries, they are maintained separately. In such cases it may be possible to consolidate the two lists into one, representing another opportunity for collaboration and mutual benefit between the two agencies. ${ }^{14}$

Taxpayer registries are maintained by tax authorities to monitor and enhance taxpayer compliance. An effective taxpayer registry would be based on a clear legislative requirement to register for tax purposes; an identifiable taxpayer population for each type of tax type; a system for uniquely identifying taxpayers, usually with numbers; and procedures to update and maintain the registry. ${ }^{15}$ Taxpayer registries are used to support analysis of taxpayer behavior and to monitor and address compliance risk.

\section{Business registers are maintained by NSOs to guide data collection and to select} samples for economic surveys. They record industry classifications and possible changes according to ISIC Revision $4 .{ }^{16}$ They also track entry and exit, and allocate appropriate enterprise sizes. In setting up or updating a business register, the NSO can usefully

\footnotetext{
${ }^{14}$ Software programs can be useful for comparing business registers with tax registries to identify duplicate enterprises or match similar enterprises across different registers.

${ }^{15}$ Lemgruber and others, 2015, Page 33.

${ }^{16}$ In many countries, the ISIC classifications are out of date-ISIC Rev. 3 or earlier — or may be poor quality, and thus would not capture economic activity in line with best practices. ISIC classification is preferable to revenue coding since the revenue authorities may not have sufficient incentive to maintain the revenue coding.
} 
collaborate with the tax authority, including by supplementing its own data with metadata from the tax authority, and including business contact details and physical locations. It can also look to augment tax authority data with data from other sources, engaging other interested parties for support and possible co-funding.

\section{USE of TAX Data In The National ACCounts: Some Country EXPerienceS}

Countries at different levels of development have successfully included administrative data in their statistical frameworks. Canada, Chile, Denmark, Finland, Guatemala, Pacific Island countries, Rwanda, Uganda, and the United Kingdom are examples of countries that use VAT and income tax records in compiling their monthly indices of economic activity, quarterly national accounts, annual GDP, and business registers. This has replaced business surveys, thus reducing the reporting burden and data collection costs associated with compiling their national accounts. These countries were selected owing to their different levels of development and the availability of information on their use of tax data for compiling national accounts.

\section{Canada}

In 2002, Statistics Canada launched the Strategic Streamlining Initiative (SSI). ${ }^{17}$ This initiative promoted expanded use and better integration of tax data in economic statistical programs. It also aimed to reduce reporting burden and data collection costs and to obtain new, higher quality statistical data. One of the projects undertaken under the SSI involved the use of Goods and Services Tax (GST) data for simple establishments to replace sub-annual surveys. Statistics Canada signed an agreement with the Canada Revenue Authority (CRA) to obtain access to all tax microdata. ${ }^{18} \mathrm{GST}$ data are reported monthly for large companies, quarterly for average sized companies, and annually for small companies. Small- and medium-sized businesses represent 93 percent of businesses, but account for only 20 percent of total revenue in the economy. The objective of the GST project was to replace monthly survey samples for 50 percent of the smaller establishments with GST data. ${ }^{19}$

The Unified Enterprise Survey (UES) initiative has cut the reporting burden for smaller enterprises. ${ }^{20}$ Over 50 percent of simple businesses have stopped receiving UES questionnaires as survey data are being replaced with administrative tax data. Any establishment accounting for 10 percent or less of the revenue of its "stratum" (its four-digit

\footnotetext{
${ }^{17}$ See Pier, Louis and Marie Brodeur, Statistical Use of Goods and Services Tax Data in Statistics Canada's Monthly Economic Surveys, Statistics Canada, Pages 1 and 2.

${ }^{18}$ This agreement fell under the jurisdiction of two acts-the Statistics Act, and the Income Tax and Excise Tax Act.

${ }^{19}$ Because the majority of these establishments were medium-sized companies, it was necessary to estimate monthly data from quarterly data, which required combining survey data with GST data.

${ }^{20}$ See Brodeur, pages 7 and 8 and Statistics Canada 1999.
} 
North American Industry Classification System) in its province is excluded from the survey; a randomly selected sample of half of the smaller of the remaining businesses - separated by size - is surveyed; and the largest businesses are subjected to a full census overseen by sector specialists. The gaps are filled with administrative tax data. Statistics Canada has also implemented a systems infrastructure that integrates tax data and ensures that they are available in a systematic way for business surveys.

The Canadian Business Register is updated on a continuous basis (Brodeur 2006). For most enterprises, the sources for updates are administrative files produced by the CRA. Among their legal obligations, enterprises must submit GST/VAT, payroll deductions retained from employees, and annual income tax forms to the CRA. For large and complex enterprises, updating is achieved by contacting the enterprise directly; a manual process undertaken by the Business Register Division. GST and payroll deduction files, obtained monthly, provide information on activity as well as new entrants. Enterprises also provide information, such as number of employees (payroll deduction), taxable sales (GST), or the size of the enterprise. Annual income tax files provide detailed pictures of each enterprise, both incorporated businesses and unincorporated businesses.

\section{Research continues on the use of tax data to further reduce reporting burden.}

Simulations have been done to test the impacts of different rates of replacement of survey data with tax data for simple enterprises. The results are that small samples of simple businesses or characteristics surveys are adequate to accurately measure economic activity.

\section{Chile $^{21}$}

In Chile, tax data are used to measure a variety of national accounts indicators. These include the Monthly Indicator of Economic Activity (IMACEC), the production accounts, and the sectoral accounts. Several of the activities that make up the IMACEC are measured using monthly value added tax returns. ${ }^{22}$ Quarterly production accounts for some industries are measured using VAT returns, and annual accounts are measured using income tax returns, which make good proxies for production accounts. ${ }^{23}$ In the sectoral accounts, the non-financial companies sector is measured using supervisory data complemented by income tax returns for unsupervised companies. This allows for the measurement of assets, liabilities, equity, inventories, accounts receivable, interest expenses, depreciation, and others, and to calculate both the current and the accumulation accounts. Finally, financial stability measures are also estimated using tax data.

\footnotetext{
${ }^{21}$ Fernández, Ivette, Use of Tax Micro-data for the Compilation of the Chilean National Accounts, IFC Bulletin No 37 165, Central Bank of Chile, Page 166.

${ }^{22}$ These include some manufacturing industries, wholesale and retail trade, the hospitality industry, some transport services, the business services, the private health sector, and "other" services.

${ }^{23}$ For example, output can be estimated using sales revenues, intermediate consumption using cost of sale, and gross value added using wages and depreciation.
} 
Chile has also explored the benefits of merging administrative data. This topic is the main focus of the Statistical Plan 2018-2022 of the Central Bank of Chile, which looks at the need for institutional coordination and the potential gains from of academic research and applied public policy. See video presentation at https://www.youtube.com/watch? $\mathrm{v}=1$ Jaogweohgg\&t=2s .

\section{Denmark $^{24}$}

\section{Statistics Denmark is a global leader in producing statistics based on administrative} data. Since the early 1970s, it has gradually replaced traditional questionnaire censuses with register-based censuses, in which census data are collected using administrative data. Today, Denmark can conduct censuses at minimal cost; the total cost of the 2011 official census was only about US $\$ 150,000$. Statistics Denmark also uses administrative data to produce other key statistics, such as education, unemployment, income (national accounts), environmental accounts, and business statistics.

Statistics Denmark is seeking to expand the use administrative data to improve both monitoring of the Sustainable Development Goals (SDGs) and the statistical systems of beneficiaries. The focus would be on population and vital statistics, but it could be extended to other statistical domains, such as education or business.

\section{Finland 25}

Finland has used administrative data, including VAT data, to improve efficiency and data quality. Statistics Finland has increased cost-effectiveness and enhanced data coverage while decreasing enterprises' reporting burden. They believe that further improvements could be realized if their cooperation with the tax authority could result in the tax authority taking statistical needs into account in selecting data to collect.

VAT data are the main source for monthly business turnover. All enterprises with an annual turnover of over EUR 8,500 are covered and as a result 93 percent of enterprises accounting for an estimated 99.8 percent of turnover report their VAT data monthly. In addition to primary production, all commercial sales of products and services are subject to the VAT. VAT and Pay As You Earn (PAYE) data are also used to calculate wages and salaries (manufacturing, trade, services and construction), monthly GDP, and the business sector in quarterly national accounts. They are used to expand coverage and for quality checks in the Business Register, structural business statistics, commodity statistics, labor cost statistics,

\footnotetext{
${ }^{24}$ Statistics Denmark, Administrative Data in Production of Official Statistics-An Initiative on How to Enhance Data Coverage in Relation to Sustainable Development Goals and Targets (SDG) and the National Statistical Systems in General, March 3, 2016.

25 Paavilainen, Paula, Efficient Use of Administrative Data in the Production of Economic Statistics in Finland, Statistics Finland Business Trends, FIN-00022, Statistics Finland, Pages 2, 3, 4, and 10.
} 
and the index of industrial output. VAT and PAYE data are used in the compilation of short-term business statistics since 1999 to comply with the 1998 EU Regulation on ShortTerm Business Statistics (1168/98). Since the 2010 tax reform, this extensive data set has been known as periodic tax return data.

Administrative data also complement survey data and Business Register data. The Business Register is updated monthly from administrative sources, including identifying starts of legal units, updating sizes of enterprises, and investigating structural changes.

\section{Guatemala $^{26}$}

In Guatemala, tax records are used to derive various components of the Monthly Index of Economic Activity (MIEA), launched in 2007. The Bank of Guatemala has informally agreed with the Tax Administration Office on the sharing of data on sales classified by industry, thus enhancing the frequency, timeliness, detail, and coverage of the data at almost no cost, and allowing for the compilation of quarterly national accounts. Furthermore, statistical processing enabled the derivation of new series for various activities.

\section{Pacific Island Countries ${ }^{27}$}

Many Pacific Island countries levy a VAT and businesses may also be subject to income tax. The VAT system requires registered business to report monthly on sales, purchases, and other details, and if this information is provided for most large businesses it can yield a useful indicator of economic activity for the national accounts. ${ }^{28}$ Using VAT sales as a measure of industry size and the annual tax accounts of the taxpayers above the VAT threshold as a measure of the formal sector, value added by industry can be obtained. This approach is faster, more comprehensive, less resource demanding, and cheaper than running a business survey.

In about half the countries, an MoU has been set up between the tax administration and the statistics office. If business names are provided data confidentiality is preserved under the Statistics Act. A working group established by the Pacific Statistics Steering Committee is preparing an MoU template to assist countries that have yet to adopt an MoU.

\footnotetext{
${ }^{26}$ Technical Assistance on MIEA and QNA, IMF CAPTAC-DR, 2012-2013.

${ }^{27}$ Freeman, Russel, The Use of Administrative Data in the Pacific Island Countries, LTX News, IMF, November 2015.

${ }^{28}$ Data on purchases collected from VAT do not include all intermediate costs as defined in the national accounts, and estimates of value added using these data may therefore have a downward bias. Fortunately, this bias can be eliminated by obtaining additional data from annual income tax returns which measure capital correctly and provide additional data not available from VAT records.
} 


\section{Rwanda}

Rwanda makes extensive use of VAT sales data in compiling annual and quarterly GDP accounts. Data on 19,000 VAT reporters are submitted quarterly and 31,000 income tax submissions are shared annually with the National Institute of Statistics of Rwanda (NISR) in a standard format each month. The NISR also maintains a register of firms and their classification through its triennial Establishment Census and annual Integrated Business Enterprise Survey, and works with the National Bank of Rwanda on administrative support and development funding.

\section{Uganda}

In Uganda, VAT turnover data are used to produce the monthly index of industrial production. The Uganda Bureau of Statistics (UBoS) and the Uganda Revenue Authority (URA) adopted an MoU in 2008 to ensure the transfer of these data and to restrict their use to "compiling aggregate statistics needed for the monitoring and analysis of economic developments and for drawing of samples of businesses necessary for conducting economic surveys." To provide a reciprocal benefit, it stipulates that the UBoS must work with the URA to improve the quality of the supplied data. The MoU also specifies a timetable for data delivery, and data formats.

The UBoS maintains records on the approximately 60,000 firms on the tax register. These records are updated each month based on data from the URA, and include both fiscal and calendar year data for sales. Enterprise level data are used for compiling output and intermediate consumption and supplement other company data. Designated Contact Officers manage the exchange of data, a Liaison Committee oversees day to day technical coordination.

\section{United Kingdom}

The UK has taken steps to expand its use of administrative data. The overwhelming primary source of information for the Office of National Statistics (ONS) has been regular surveys of businesses and households, with relatively little use made of administrative data and still less of other (and growing) sources of big data. (Bean 2016). In large part, this reflects the cumbersome legal framework, which needs to be modified.

An extensive development program has been undertaken to use administrative data from Her Majesty's Revenue and Customs VAT turnover data as a data source within the compilation of the output approach to GDP. The approach has been to use VAT 
turnover to supplement turnover estimates from the Monthly Business Survey. ${ }^{29}$ Pilot changes commenced in the summer of 2016, 20 candidate industries were selected, and the UK has been testing and improving the processing of the data. ${ }^{30}$

For the first time, the ONS is using VAT turnover data from 630,000 businesses within GDP estimates, published on December 22, 2017. This represents a significant advance in the transformation of UK national accounts and short-term economic indicators.

New technology and methods have been developed, which allow the UK to use VAT turnover to supplement data from 45,000 businesses selected as part of the Monthly Business Survey. This will enable the UK to transform short-term turnover statistics by the end of 2020, cutting the survey burden on small- and medium-sized businesses while allowing it to deliver more detailed regional and industrial data. ${ }^{31}$

\section{United States}

The United States promotes expanded use of administrative data. A February 2014 memo published by the Office of Management and Budget called for expanded use of administrative data, asking heads of executive departments and agencies to work to identify administrative datasets with potential for statistical use. The memo covers a broad range of data, including data on labor markets, crime, and public health. It lays out data stewardship practices, including policies to restrict access and disclosure to ensure confidentiality, removing identifiable information when not needed, and laying out legal responsibilities to protect privacy. It also calls for documentation of data quality, and interagency agreements to govern the transfer of data.

\section{In 2016 the U.S. Congress passed the Evidence-Based Policymaking Commission Act.} This act established an executive branch Commission on Evidence-Based Policymaking, tasked with conducting a comprehensive study of the data inventory, data infrastructure, database security, and statistical protocols related to Federal policymaking to determine the optimal arrangement for integrating administrative data on Federal programs and tax expenditures, survey data, and related statistical data series while weighing the security of personally-identifiable information or records. The Commission issued its final report in September 2017 (https://www.cep.gov/cep-final-report.html).

\footnotetext{
${ }^{29}$ Stephens, Mark and John Allcoat, Ibiden, Pages 2 and 3.

${ }^{30}$ Allcoat, John, Methodology: HMRC VAT update April 2016, Office for National Statistics, United Kingdom, April 4, 2016, Pages 1, 2 and 3.

${ }^{31}$ Stephens Mark, VAT Turnover Implementation into National Accounts: December 2017 Update, Office for National Statistics, December 22, 2017, Page 1.
} 


\section{CONCLusion}

NSOs are increasingly relying on administrative data to enhance statistical reporting in a wide range of datasets and sidestep a growing resistance to the collection of economic censuses and business surveys. This paper argues that tax data can be used to improve the timeliness, coverage, and quality of national accounts data while reducing costs and reporting burdens. It is important to verify that registration and filing rates for taxation are adequate, but an examination of 90 countries during 2011-2015 finds that the VAT and corporate income tax registration and filing rates are adequate for national accounts compilation purposes for almost all countries across different income groups.

Several concerns may need to be addressed before using administrative data for statistical purposes. First, confidentiality concerns, legally mandated or otherwise, need to be addressed, including with partially anonymized data, restricted access to tax records by NSO staff, and sanctions for breaches of confidentiality. Administrative data typically need to be reorganized before they can be used for statistical purposes, though this is generally far more economical than alternative data collection methods, such as conducting surveys. Tax compliance may vary over time, so changes in taxpayer registries or in revenues need to be carefully examined to determine how they might reflect changes in output. Timing issues can arise, such as when there are differences between the dating of transactions for tax purposes and for national accounts purposes, and the industry classification of tax data may differ from that of national accounts data.

\section{Cooperation between NSOs and providers of administrative data, including tax} authorities, is key and should be mutually beneficial. While the benefits of cooperation to NSOs are obvious, there are also potential benefits to providers of administrative data that should be identified and exploited. Data sharing is best done through an MoU with the agency that is providing the data. Concise MoUs should spell out mutual benefits, and make clear that data will be shared for statistical purposes only. One key benefit is administrative efficiency. NSO business registers that overlap with taxpayer registries should be consolidated into one document, if possible, or at least coordinated. NSOs and tax authorities should also cooperate on data validation, data quality checks, and data security. 


\section{REFERENCES}

Allcoat, John, "Methodology: HMRC VAT update April 2016”, Office for National Statistics, United Kingdom, April 4, 2016.

Allingham, Michael Agnar and Sandmo, "Income Tax Evasion: A Theoretical Analysis", Journal of Public Economics, 1972, 323-338.

Bean Charles, Independent Review of UK Economic Statistics, March 2016.

Bloem Adriaan, Robert Dippelsman, and Nils O. Mæhle, "Quarterly National Accounts Manual, Concepts, Data Sources, and Compilation”, 2001.

Bissett D., Peter, "Use of Tax Data in the Production of Provincial Economic Statistics", Statistics Canada, 5/21/2014.

Brodeur, Marie, Use of Tax Data in the Unified Enterprise Survey (UES), Statistics Canada Workshop on Use of Administrative Data in Economics Statistics, Moscow, October 30th-November 1st, 2006.

Commission of the European Communities, International Monetary Fund, Organisation for Economic Co-operation and Development, United Nations, and World Bank, "System of National Accounts 2008”, New York, December 2009.

Duncan Cleary, William Crandall, and Andrew Masters, "Understanding Revenue Administration, Results from the Second Survey of the Revenue AdministrationFiscal Information Tool”, Fiscal Affairs Department, International Monetary Fund, 2017.

Fernández, Ivette, "Use of Tax Micro-data for the Compilation of the Chilean National Accounts", IFC Bulletin No. 37 165, Central Bank of Chile.

Freeman, Russel, The Use of Administrative Data in the Pacific Island Countries, LTX News, IMF, November 2015 (unpublished).

Grote, Martin, "How to Establish a Tax Policy Unit", How-To-Note No. 17/02, IMF, October 2017.

Lemgruber, Andrea and Andrew Masters and Duncan Clary, "Understanding Revenue Administration, An Initial Data Analysis Using the Revenue Administration Fiscal Information Tool”, Fiscal Affairs Department, International Monetary Fund, 2015.

OECD, "Improving Co-operation Between Tax and Anti-Money Laundering Authorities", September 2015. 
Paavilainen, Paula, "Efficient Use of Administrative Data in the Production of Economic Statistics in Finland", Statistics Finland Business Trends, FIN-00022, Statistics Finland, Finland, 2012.

Pier, Louis and Marie Brodeur, "Statistical Use of Goods and Services Tax Data in Statistics Canada’s Monthly Economic Surveys", Statistics Canada.

Statistics Canada, "Non-technical Background Paper on the Unified Enterprise Survey Program", June 1999.

Statistics Denmark, "Administrative Data in the Production of Official Statistics-An Initiative on How to Enhance Data Coverage in Relation to Sustainable Development Goals and Targets (SDG) and the National Statistical Systems in General", March 3, 2016.

Statistics Denmark, "Issues and Challenges Faced in Countries when Seeking to Increase Use of Administrative Data", 2017.

Stephens, Mark and John Allcoat, "Exploitation of HMRC VAT data, Office for National Statistics", United Kingdom, October 7, 2015.

Stephens, Mark, VAT Turnover Implementation into National Accounts: December 2017 Update, Office for National Statistics, December 22, 2017.

Uganda Bureau of Statistics, "Memorandum of Understanding (MoU), between UBoS and Uganda Revenue Authority", 2008.

United Nations, "International Standard Industrial Classification of All Economic Activities (ISIC)”, Rev. 4, 2008.

U.S. Office of Management and Budget, "Memorandum for the Heads of Executive Departments and Agencies”, February 2014. 


\section{Appendix I: Tools Providing an Indication of the Coverage of Tax Records: ISORA/RA-FIT, RA-GAP and TADAT}

\section{Survey data}

The International Survey on Revenue Administration is a survey for gathering information on revenue administration practices and performance to support comparative studies and benchmarking. In this survey tax authorities self-report, among other indicators, on time filing rates and payment rates. Currently data are available for fiscal years 2014 and 2015. On time filing data for 2011-13 were collected through the web-based Revenue Administration Fiscal Information Tool (RA-FIT) developed by FAD. Data for 2011 to 2015, aggregated by income groups and region, are available publicly on the associated RA-FIT Data Dissemination Platform (http://data.rafit.org ). The income groups for 2011-13 were divided according to 2012 Gross National Income (GNI) per capita, calculated using the World Bank Atlas method, and the income groups for 2014-15 were updated by the World Bank are based on 2013 data.

\section{The Tax Administration Diagnostic Tool}

The Tax Administration Diagnostic Tool (TADAT) is a multidimensional diagnostic tool aimed at identifying tax administration reform priorities. It focuses on nine key performance outcome areas: a) integrity of the registered taxpayer base, b) risk management, c) supporting voluntary compliance, d) filing of tax returns, e) payment of obligations, f) ensuring accuracy of reporting, g) tax dispute resolution, h) operational efficiency and effectiveness, and i) accountability and transparency.

\section{Tax gap analysis}

The Revenue Administration Gap Analysis Program (RA-GAP) is an IMF technical assistance service that assists tax administrations in monitoring taxpayer compliance levels through tax gap analysis, and aims to develop capacity in the country to conduct the analysis by themselves. RA-GAP estimates potential tax revenues, evaluates actual revenues, and analyses the factors causing gaps between them. When statistical data are adequate, it estimates the overall tax gap broken down into a compliance gap and a policy gap. The compliance gap can be further broken down into a collections gap and an assessment gap; and the policy gap into a non-taxable gap and an expenditure gap. This provides a basis to improve effectiveness in raising revenue, promote perceived fairness among taxpayers, and build trust in the tax system.

The countries included in Table 1 are:

Albania, Anguilla, Argentina, Barbados, Belize, Benin, Bermuda, Bolivia, Bosnia and Herzegovina, Brazil, Bulgaria, Burkina Faso, Burundi, Cameroon, Cape Verde, Central African Republic, Chad, Chile, Colombia, Republic of Congo, Democratic Republic of 
Congo, Cook Islands, Costa Rica, Cote d'Ivoire, Dominica, Dominican Republic, Ecuador, El Salvador, Ethiopia, Fiji, Gabon, The Gambia, Ghana, Grenada, Guatemala, Guinea, GuineaBissau, Honduras, Ireland, Jamaica, Jordan, Kenya, Kiribati, Kosovo, Lesotho, Liberia, Macedonia, Madagascar, Malawi, Maldives, Mali, Marshall Islands, Mauritania, Mauritius, Mexico, Micronesia, Montenegro, Montserrat, Netherlands, Nicaragua, Niger, Nigeria, Norway, Papua New Guinea, Paraguay, Peru, Philippines, Rwanda, Samoa, Senegal, Serbia, Seychelles, Sierra Leone, Solomon Islands, St. Kitts and Nevis, St. Lucia, St. Vincent and the Grenadines, Sudan, Swaziland, Tanzania, Togo, Tonga, Trinidad and Tobago, Turks and Caicos Islands, Uganda, Uruguay, Vanuatu, Virgin Islands, West Bank and Gaza, and Zambia. 


\section{Appendix II: Sample Memoranda of Understanding (MOU)}

\section{MEMorandum OF Understanding (MoU) Between Uganda BuREaU OF STATISTICS AND UGANDA REVENUE AUTHORITY}

The Uganda Bureau of Statistics (herein referred to as UBOS) has requested Uganda Revenue Authority (herein referred to as URA) to provide SEVERAL TAX STATISTICS

\section{PREAMBLE}

WHEREAS it has become necessary to formalise the procedures relating to the flow of accurate and timely domestic tax data which form a vital element in the compilation of gross domestic product (in current and constant prices) and as such provide analysis of annual periodic variations in the various economic sectors, thus quantifying developments in the UGANDA, the parties to this agreement DO HEREBY agree to formalise the procedures on the following conditions and terms:

\section{PARAGRAPH 1.}

Definitions

In this memorandum of understanding, unless the context otherwise stipulates;

"Agreement" means the service level understanding entered herein between the two mentioned parties;

"Chief Contact Officers" means the Executive Director, UBOS and the Commissioner General URA;

"Contact Officers' means designated officials at both UBOS, and URA;

"URA" means The Uganda Revenue Authority;

"UBOS" means The Uganda Bureau of Statistics;

"VAT" Means Value Added Tax;

"PAYE" Means Pay as You Earn;

NOW THEREFORE THIS MEMORANDUM OF UNDERSTANDING WITHNESSETH as follows: 


\section{PARAGRAPH 2.}

General Responsibilities

1. URA shall provide to Uganda Bureau of Statistics timely Tax statistics on a regular basis as summarized traders' returns on a monthly basis.

2. UBOS undertakes to use the data supplied for purposes of: Only compiling aggregate statistics needed for the monitoring and analysis of economic developments and for drawing of samples of businesses necessary for conducting economic surveys

3. UBOS on the basis of data supplied shall work with URA to improve data quality and where necessary make improvements to sourcing and processing systems to the benefit of both parties.

4. UBOS undertakes to consult URA on any requirements that might be included in surveys conducted by UBOS and provide any other statistical advice whenever called upon.

\section{PARAGRAPH 3.}

\section{Security and Confidentiality}

1. UBOS shall not allow the data supplied by URA to be used for any other purposes other than for statistical inferences.

2. Any data to be released shall be in an anonymous format in order to up hold the confidentiality of the affairs of the taxpayers.

\section{PARAGRAPH 4.}

\section{Contact Officers}

1. UBOS and URA shall have contact officers whose names and official titles shall be communicated to either party.

2. The contact officers shall form a liaison committee that shall be in charge of the day to day technical coordination of the operation of this understanding and as well act as liaison officers between the two parties to this agreement.

3. The liaison committee shall meet within a week after data exchange in alternate locations and with alternate chairpersons to discuss common problems and identify appropriate solutions.

4. The contact officers shall report to their Chief Executive Officers who shall be the chief contact officers. 


\section{PARAGRAPH 5.}

Transmission of Information

1. URA shall supply UBOS with the data according to regular timetables, using secure modes of data exchange and in formats that will be agreed upon between the parties.

2. At the supply of the information, URA shall advise UBOS of any changes or up dates to the information handling and processing deemed important to its use.

3. In the event of major disruptions to processing and transmission of the data and associated information; URA shall notify UBOS of the problem and the effect on its timeliness as soon as possible in advance.

\section{PARAGRAPH 6.}

Accuracy and Quality of the Statistics and Information

1. URA shall carry out normal processes including data editing needed to ensure that Tax statistics are of acceptable quality.

2. UBOS on the basis of data supplied shall monitor its quality and shall immediately inform URA of any discrepancies or problems detected in the data.

3. UBOS and the URA shall have/hold regular meetings to review the status of the data and statistics compiled during the processing.

4. UBOS shall to any extent possible provide the statistics generated to URA in an agreed format before their release to the general public

\section{PARAGRAPH 7.}

\section{Amendments}

1. The parties to this memorandum of understanding shall mutually agree upon any amendment to this arrangement and this shall be in writing.

\section{PARAGRAPH 8.}

\section{Miscellaneous Provisions}

1. A party to this understanding shall not re-assign any of its obligations under this Agreement to any third party without the written consent of the other party. Any changes in officers shall as well be communicated to either party. 
2. Whereas emphasis of documentation in this understanding has been on Tax statistics, it is categorically re stated hereof that: Information obtained from URA by UBOS under this understanding shall not only limit to the above but extend to any other information as of when statistical need arises.

\section{PARAGRAPH 9.}

\section{Settlement of Disputes}

URA AND UBOS shall co-operate to resolve amicably, any disagreement or dispute arising out of the interpretation or execution of this memorandum of understanding.

\section{PRAGRAPH 10.}

\section{Termination and Continuity of Obligation}

1. Either party to this MOU may terminate the Agreement by serving to the other party in written a three months' notice of intention to terminate.

2. The termination shall take effect, on agreement of the two parties at the end of the three months from the date of service of the notice.

3. A party to this Agreement, that terminates the Agreement, shall continue to perform its outstanding obligations under this understanding.

\section{PARAGRAPH 11.}

\section{Force Majeure}

If any party to this MOU is prevented from implementing its obligation due to civil strife or any unforeseeable natural and technological calamities, the operation of this Agreement shall be suspended until the said events are resolved.

\section{PARAGRAPH 12.}

\section{Commencement}

This Agreement shall come into effect on the date of signing by both parties.

IN WITNESS HEREWITH, the undersigned being the duly authorized representatives on behalf of their agencies as partners to this memorandum of understanding signed in 6 copies at this place, date and year written below.

At .........................................on the

day of. 2008 
For and on behalf of Uganda Bureau of Statistics

Executive Director

Secretary to the Board

\section{For and on behalf of Uganda Revenue Authority}

Commissioner General

Board Secretary 


\section{Memorandum of Understanding (MoU) Between The Gambia ReVEnUe AUTHORITY (GRA) AND THE GAMBia BUREAU OF STATistics (GBoS)}

Agreement relating to the coordination, sharing, updating and periodic reporting of VAT data and Business Register data, signed on January 6, 2016, between the Gambia Revenue Authority (GRA) and the Gambia Bureau of Statistics (GBoS).

The Gambia Revenue Authority (GRA) is legally hereby represented by the Commissioner General and,

The Gambia Bureau of Statistics (GBoS) is legally represented by the Statistician General.

Considerations:

Reference is made to the meeting held at GRA Head Quarters on $30^{\text {th }}$ September 2014 between GRA, GBoS and IMF to discussing the production of VAT statistics for quarterly Gross Domestic Product (GDP) estimates and the development, maintenance of the Business Register in The Gambia.

The two parties agreed on the following points:

Recognise that this agreement is part of a framework agreement between the Gambia Revenue Authority (GRA) and the Gambia Bureau of Statistics (GBoS);

Recognise that data and evidence from data is central to the national policy and planning process and must form the basis of practices in every sector for monitoring, evaluation and impact assessment;

Recognise the great need to enhance the coordination of the National Statistical System in The Gambia in general and the use of VAT data for quarterly Gross Domestic Product (GDP) estimates and the development of the Business Register in particular;

Recognise that the Gambia Bureau of Statistics is the state-mandated agency for coordinating the National statistical System, reporting and disseminating official statistics within the country;

Note that to fulfil this mandate the Gambia Bureau of Statistics publishes and disseminates statistical reports on a regular basis, in particular the annual and quarterly Gross Domestic Product (GDP) estimates, and maintaining the Business register;

Express that it is imperative for the Gambia Bureau of Statistics to collect, compile report and disseminate data from various sources; 
Note that the Gambia Revenue Authority (GRA) is the leading Government Agency, mandated to collect taxes and has the technical expertise in the production and reporting of tax related data;

Note that the Gambia Revenue Authority (GRA) is prevented from the disclosure of any information under Section 255 of the Income and Value Added Tax Act 2012, except to a person in the service of the Government of The Gambia in a revenue or statistical department, if the disclosure is necessary for the performance of the person's official duties;

Note that the Gambia Revenue Authority (GRA) has an extensive database of taxpayers operating businesses in The Gambia, each with an assigned Tax Identification Number (TIN);

Recognise that the Gambia Revenue Authority (GRA) systems would be a significant source of the necessary updates of the Business Register;

Recognise that the Gambia Bureau of Statistics (GBoS) and the Gambia Revenue Authority (GRA)will work together to improve the Business Register by classifying businesses according to "International Standard Industrial Classification (ISIC Rev 4) in order to allow the data to be used for the production of quarterly GDP estimates;

Recognise that GBoS and GRA will work together to develop a Business Register and procedures needed to keep the Business Register maintained;

Express that it is crucial for GBoS and GRA to set up a Working Group to take forward the above mentioned issues and other areas of mutual interest;

\section{Article 1: $\quad$ Purpose of the Agreement}

1. The present MOU is not a legally binding contract. It is intended to provide a clear understanding of the services provided by parties, and their respective roles and responsibilities.

2. The purpose of this MOU is to provide a working group framework for the coordination, exchange and reporting data; to set out the respective areas of responsibilities in tax data in particular VAT data and business register related data at national level of the Gambia Revenue Authority (GRA) and the Gambia Bureau of Statistics (GBoS); to note the forms in which cooperation between GRA and GBoS will take; and to set down a procedure for resolving disagreements. The aim of these arrangements is to avoid duplication of statistical work, to prevent conflicting requests for data from users; and to promote high quality and consistent statistics at national level for the use of policy-makers and the general public. 


\section{Article 2: $\quad$ Role of parties and working arrangements}

1. The GBoS and GRA have shared responsibility to set up a joint working group to take forward cooperation between the two agencies. Clearly, this working group will:

- Take forward the design and implementation of the Business Register. This includes also developing rules associated with the matching and reconciling of business entities identified by each agency, birthing and deathing procedures, industry coding, and updating the other variables. Eventually leading to one register:

- Analyse VAT data overtime according to ISIC Rev 4 and assess whether it is reliable enough to be used for quarterly GDP estimates;

2. The Gambia Revenue Authority (GRA) will provide GBoS with the following data, on time:

- $\quad \boldsymbol{V A T}$ data: the GRA will provide GBoS with quarterly VAT data based on International Standards Industrial Classification (ISIC Rev.4) for its use in the quarterly GDP estimates and for publication in the quarterly statistics abstract.

- Updates on Business register: the GRA will provide GBoS with information needed to develop and maintain the Business Register.

- Import and Export data: GRA will provide on time to the GBoS external trade statistics (including exports and imports data) for the compilation of external trade statistics quarterly report as well as the development of Export and Import Price Index (XMPI).

3. The Gambia Bureau of Statistics $(\mathrm{GBoS})$ will provide GRA on time with the following data:

- Industry Coding: GBoS will assist GRA in industry coding on ongoing basis using ISIC Rev. 4.

- National Accounts statistics: GDP estimates will be available annually according to the release calendar of GBoS and communicated to GRA. Once the quarterly GDP is developed and ready for release, it will be shared with GRA.

- External Trade statistics: quarterly external trade statistics report will be shared with GRA as well as XMPI once it is developed.

- Business Register: updated structure of the Business Register according to ISIC Rev 4 will be shared with GRA, subject to statistics confidentiality as defined by the Statistics Act 2005.

- Price statistics, including monthly Consumer price index and producer price index. The CPI will be made available every 15 th of the month following the CPI 
reference month. PPI will be made available every quarter. All these products will be made available and submitted to the GRA.

- Social indicators: GBoS will provide GRA with the needed social indicators and population projections, gathered from surveys and censuses or other administrative sources.

\section{Article 3: $\quad$ Planning and time of delivery}

1. The GBoS needs a quick and reliable access to data compiled by GRA, and GRA needs similar access to data compiled by the GBoS. The parties agree for the timely exchange of electronic data, including individual records, as it may be deemed necessary, subject to the respect of statistical confidentiality.

2. The delivery of the data to each institution will be done following their respective production and publication timeframes. The condition is that both institutions that have to present data will do so in time. Both GRA and GBoS will discuss this and will draft a document that list the agreements made.

\section{Article 4: Quality standards}

The data to be delivered to each institution will have to meet the defined quality standards.

\section{Article 5: Use of resources}

The needed capacity for each institution to meet this agreement will be defined in their respective annual budget. Where it causes significant new workload demand, the provision of the data will be subject to the department's ability to reallocate or receive new funding for the required resources.

\section{Article 6: Leadership, Cooperation and Communication.}

1. For this agreement, the relevant leading technical unit of the Gambia Revenue Authority (GRA) is legally represented by the Deputy Director, Policy Planning \& Research, and

2. The relevant leading technical unit of the Gambia Bureau of Statistics (GBoS) is legally represented by the Director of National Accounts Statistics.

3. The GRA and GBoS will cooperate through bilateral contacts, through participation in working meetings and committees, through the National Statistics Council (NSC) meetings and through the Conference of Official Statistics annual meetings by users and producers. 
4. Management on a daily basis will be run by the Principal Statistician in charge of Business Enterprise Surveys of GBoS and the Deputy Director, Policy Planning \& Research of the GRA, who will be the designated Working Group leaders for their agencies.

5. To guarantee an orderly flow of work, the working group will be supervised by a Management Committee. The Management Committee will be formed, for GRA, by the Commissioner of Domestic Taxes, Deputy Director Policy Planning \& Research, Manager of GamTaxNet; and for GBoS, by the Director of Quality, Coordination and Dissemination; the Director of National Accounts; the Director of Prices and Government Finance Statistics; the Principal Statistician in charge of Business Enterprise Surveys in National Accounts Unit. Other members include the Director of Registrar of Companies, the Director of the Gambia Tourism Board, and the Director of the Chamber of Commerce.

6. At least once a quarter the Working Group leaders will report to the Management Committee.

7. To the extent possible, disagreement between the GRA and GBoS on the interpretation and execution of this MOU will be resolved at the Working Group level. Where no agreement can be reached at this level, the Commissioner of Domestic Taxes of the GRA and the Director of National Accounts of the GBoS will endeavour to resolve the issue. Where they are unable to do so, the Management Committee will endeavour to come to an agreement.

8. All matters that are not defined in this agreement will be decided upon by the Management Committee.

9. The signatories represent the institutions providing relevant statistics covered by this MOU. They will oversee the implementation of the MOU.

\section{Article 7: Costs, invoicing, payments}

Both GRA and GBoS will not claim any cost from each other. However, the two institutions will share costs for carrying out some relevant statistical activities if need arises.

\section{Article 8: Copyrights, Authorship and Reproduction of data}

1. The copyright of the work done by both GRA and GBoS will remain with the relevant institution. The two institutions can make use of that according to the established rules. 
2. The GRA and GBoS may reproduce, in electronic or hard copy publications, data compiled by the other party. In principle, both parties may reproduce the data as most recently released by the other party as a prime source. The data may be aggregated, or seasonally adjusted in a different way by the party reproducing them without reference to the other party. The parties shall consult each other on any other major modification to the data published.

\section{Article 9: Confidentiality}

Data provided to GBoS by GRA is subject to the Secrecy laws of the Income and Value Added Tax Act 2012, that being that the information received shall be used by the GBoS officer solely for the performance of their duties, and that the information in regards to individual records is treated as confidential and not to be disclosed to other parties.

Data provided to GBoS or submitted by GBoS to other agencies are subject to the protection of confidentiality of individual records or any other aggregation that can allow identification of individual records according to the Statistics Act 2005.

\section{Article 10: Duration of the agreement and updates}

This agreement will last as long as it may be deemed necessary. This MOU is effective from January 6, 2016. Its operation will be monitored and will be reviewed annually. At the request of either party, the GRA and GBoS may review and update this MOU. (GBoS) 